\title{
CORRECTIONS
}

\section{CT retinal detachment}

An error in our editorial processes led to a mistake in the title of this Minerva picture by Simon Kolb and colleagues (BMJ 2013;347:f4613, doi:10.1136/bmj.f4613). The title should be "CT postoperative retinal detachment" rather than "CT retinal ๑ BMJ Publishing Group Ltd 2013 detachment." 